\title{
Density functional theory study of substitutional oxygen in diamond
}

\author{
K.M. Etmim 11, P.R. Briddon ${ }^{2}$, A.M. Abutruma ${ }^{3}$, A. Sghayer ${ }^{11}$, S.S. Farhat ${ }^{1}$ \\ 1 Physics Department, Faculty of Science, University of Tripoli, Tripoli, Libya \\ 2 School of Electrical, Electronic and Computer Engineering Newcastle University, \\ Newcastle upon Tyne, England, NE1 7RU, UK \\ 3 High Institute for Comprehensive Professions (Al-Shmokh Institution), Tripoli, Libya
}

Received July 20, 2015, in final form December 22, 2015

\begin{abstract}
A few studies have been recently presented for the existence of oxygen in diamond, for example, the N3 EPR centres have been theoretically and experimentally assigned the model made up from complex of substitutional nitrogen and substitutional oxygen as nearest neighbours. We present ab initio calculations of substitutional oxygen in diamond in terms of stability, electronic structures, geometry and hyperfine interaction and show that substitutional oxygen with $\mathrm{C}_{2 v}, S=1$ is the ground state configuration. We find that oxygen produces either a donor or acceptor level depending on the position of the Fermi level.
\end{abstract}

Key words: density functional theory, diamond, oxygen, hyperfine interaction

PACS: 31.15.E-, 81.05.ug, 31.30.Gs

\section{Introduction}

High electron and hole mobilities at room temperature and unrivalled thermal conductivity at room temperature, mean that diamond could be the material of choice for high-power and high-frequency electronics. Many defects in a diamond such as nitrogen [1-3] and boron [4] are the main chemical elements now well identified. Nitrogen as a simple substitutional defect forms a deep level at $1.7 \mathrm{eV}$ [5] below the conduction band edge and the boron gives a shallower level at $0.37 \mathrm{eV}$ above the edge of the valence band [6]. For this reason, a variety of other chemical defects in a diamond are now being investigated.

Oxygen is expected to be one of important impurities in a diamond due to its relatively close size of carbon atom and abundance, and its has been suggested to lead to n-type conductivity in a diamond [7]. Experimentally, oxygen was found in mineral inclusions in a diamond [8] and combustion analysis of converting diamond to graphite indicated high levels of oxygen in natural diamond [9]. Moreover, a small number of optical centres may be related to oxygen [10, 11].

Electron-paramagnetic-resonance (EPR) spectroscopy is a powerful probe used to identify enormous centres in diamond with nucleus spin of none zero. A small percentage $(0.04 \%)$ of natural oxygen is ${ }^{17} \mathrm{O}$ [12] which is consistent with little evidence of the involvement of oxygen in electron paramagnetic resonance centres in diamond [13]. However, enrichment of diamond in the ${ }^{17} \mathrm{O}$ isotope can occur during diamond growth [12] or ${ }^{17} \mathrm{O}$ ion implantation [7, 12] where the former undergoes insufficient control of the gas environment during diamond growth [12], and the latter is induced by lattice damage where the oxygen may be trapped for instant vacancy. EPR centre called KUL12 was detected to be an $S=1 / 2$ centre interacting with one $I=5 / 2$ nucleus with $A_{\|}=-362 \mathrm{MHz}$ and $A_{\perp}=-315 \mathrm{MHz}$. Unfortunately, there is no other direct measurement of this centre.

The N3 and OK1 centres have been suggested to contain oxygen; the former in a nearest neighbour nitrogen-oxygen pair, and the latter in a second nearest neighbour nitrogen-oxygen pair. Previously, we analysed N3 and OK1 in a broader study [14] and we concluded that the most suitable candidate structure for $\mathrm{N} 3$ is $\mathrm{N}_{s}-\mathrm{O}_{s}$. For OK1, none of the proposed models yield hyperfine tensors in agreement with 
experiment. Three of the EPR centres found in synthetic diamonds grown in carbonate medium in recent experimental study [15], using the high pressure apparatus BARS [16, 17] showed that OX1, OX2 and OX3 centres are oxygen atoms occupying substitutional, interstitial and next to vacancy sites, respectively.

The previous theoretical work using ab initio calculations [18] shows that substitutional oxygen exhibits carbon vacancy character which gives rise to an occupied $a$-level into the middle of the band gap and unoccupied $t$-level just below the conduction band. A theoretical work has predicted that oxygen introduces a mid-gap donor level in the band gap of a diamond, which is above the fundamental level of vacancy being $2 \mathrm{eV}$ above the top of valence band. So, in a material containing both types of centres, one would expect a charge transfer to occur, which gives rise to EPR active defect.

In this work, extensive calculations on different models containing oxygen atoms were carried out, and the total energies and other properties of defects were determined using ab initio calculations.

\section{Method}

The structures were modelled using density-functional calculations with the exchange-correlation in a generalised gradient approximation [19] by the AIMPRO code [20, 21]. The Brillouin-zone is sampled using the Monkhorst-Pack scheme [22] with a uniform mesh of $2 \times 2 \times 2$ special $k$-points. For several sample structures, we calculated the total energies using a $4 \times 4 \times 4$ mesh, which indicated that the relative total energies are converged to better than $10 \mathrm{meV}$.

The valence states were represented by a set of atom-centred $s$ - and $p$-with the addition of a set of $d$-like Gaussian functions [23] to allow for polarization, and the Kohn-Sham states were expanded with the help of a contracted basis with a total of 22 functions on each carbon and oxygen atom. For the charge density evaluation, the plane waves with a cut-off of 300 Ha were used, yielding structures optimized until the total energy changes by less than $10^{-5}$ Ha. The lattice constant and the bulk modulus were within $1 \%$ and $2 \%$, respectively, of experimentally determined values. The lattice constant was optimized, keeping the symmetry of the supercell fixed, giving a value of $3.5719 \AA$, close to the experimental value of $3.5667 \AA$ [24]. The calculated direct and indirect band gaps agree with the published plane-wave values [25] (5.68 and $4.18 \mathrm{eV})$.

In general 216-atom, simple-cubic supercells of side length $3 a_{0}$ are used. Core-electrons are eliminated by using pseudo-potentials [26], the $1 s$ electrons of $\mathrm{C}$ and $\mathrm{O}$ are in the core, and the $3 p$ electrons are treated as the valence ones, so that hyperfine interactions are obtained by reconstructing the all-electron wave functions in the core region [27, 28]. The atomic calculations for the reconstruction in the hyperfine calculations were performed using a systematic polynomial basis [29]. Electrical levels were calculated using the marker method by comparing acceptor and donor with B and N, respectively.

\section{Results and dissections}

Different charged forms $\mathrm{O}_{s}^{0}, \mathrm{O}_{s}^{+}$and $\mathrm{O}_{s}^{-}$of substitutional oxygen in diamond are examined. In all cases, the $C_{2 v}$ configuration is found to be favoured.

In the neutral charge state, we find several metastable structures for substitutional $\mathrm{O}_{s}^{0}$ in a diamond. Interestingly, the spin orientation was crucial in terms of determining the stability. The lowest in energy exhibits a $C_{2 v} S=1$, as schematically shown in figure 1(a). The oxygen atom undergoes a distortion along $\langle 001\rangle$, the oxygen moves strongly off centre to form two $\mathrm{C}-\mathrm{O}$ bonds leaving behind two $\mathrm{C}$ dangling orbitals. This suggests that it may undergo a symmetry lowering distortion, probably of a chemical rebonding. Three structures [figures[1(b), (c) and (d)] were found to be energetically indistinguishable and higher in energy than the ground state configuration by just $0.2 \mathrm{eV}$. The oxygen atom in figure 1 (c) is in a fourfold coordinated arrangement with $\mathrm{C}-\mathrm{O}$ bonds of lengths $1.73 \AA$.

A trigonally symmetric state was also examined and was found to be metastable. The $C_{3 v} S=0$ structure in the figure 1(b) exhibits a slight displacement along $\langle 111\rangle$, where one of the four neighbouring $\mathrm{C}$ atoms move from $1.73 \AA$ to $1.72 \AA$ compared to the on-site structure in figure 1 (c). The energy differences [between figure 1(b) and (c)] are just of a few meV. Symmetrically equivalent to the ground state configuration [figure 1 (a)], the spin averaged structure with two equivalent carbon neighbours to $\mathrm{O}$ is 


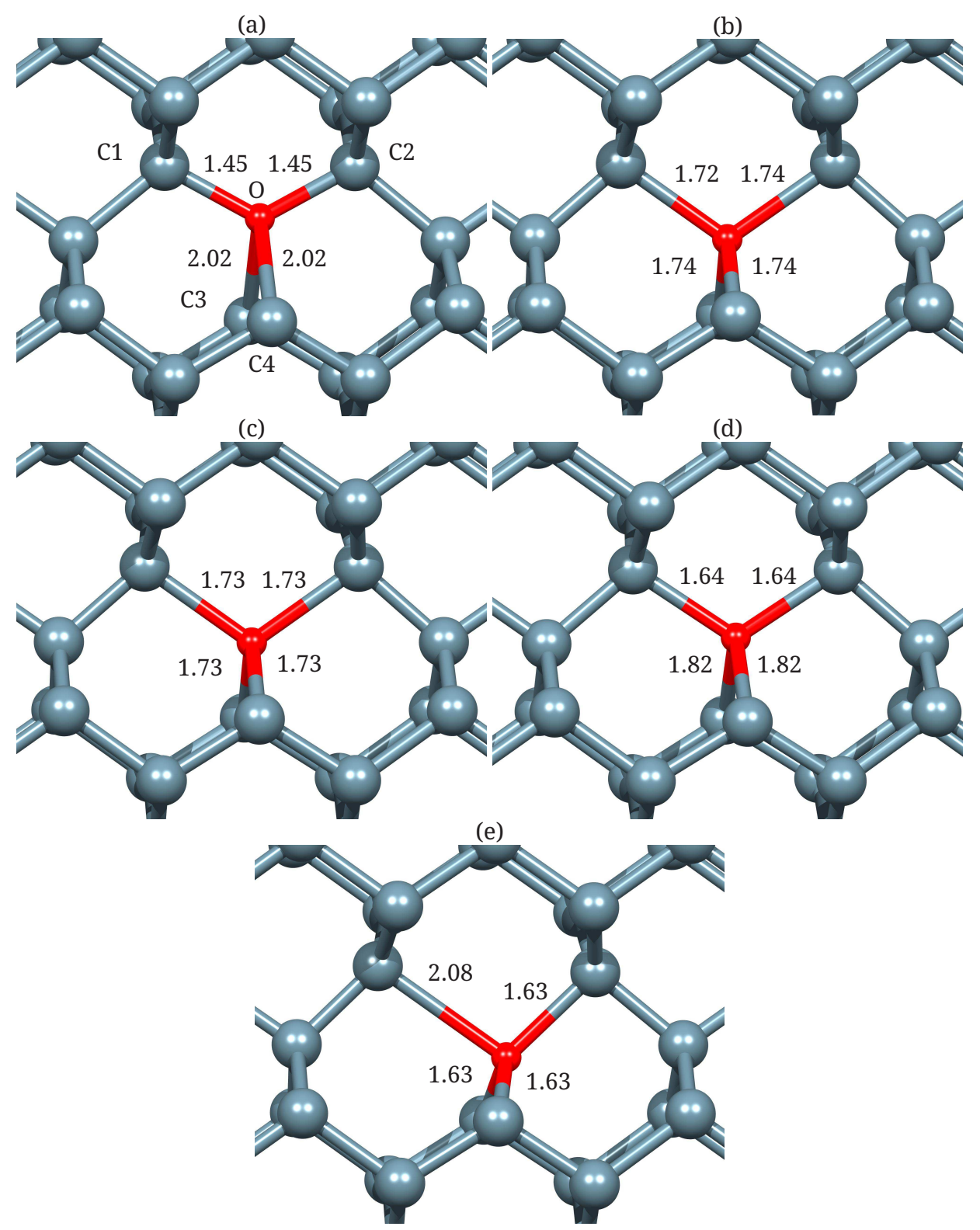

Figure 1. (Color online) Schematic structures of the substitutional oxygen in both the $S=0$ and $S=1$ configurations. Grey and red spheres represent $\mathrm{C}$ and $\mathrm{O}$. (a) $C_{2 v}, S=1$, (b) $C_{3 v}, S=0$, (c) $T_{d}, S=0$, (d) $C_{2 v}, S=0$, (e) $C_{3 v}, S=1$. Bond lengths in $\AA$.

moved closer to the impurity, lowering the symmetry to $C_{2 v}$, however, it is $0.21 \mathrm{eV}$ higher in energy than the most stable one.

The structure in the figure 1 (e) exhibits $C_{3 v} S=1$ where the oxygen is significantly displaced offsite along $\langle 111\rangle$ producing an elongated $\mathrm{C}-\mathrm{O}$ bond to $2.08 \AA$ which significantly increased the energy to $0.57 \mathrm{eV}$ compared to the most stable configuration.

Generally, the substitutional $\mathrm{O}$ atom bonds relatively weakly to the carbon dangling bonds in the vacancy, the reason for this probably being the oxygen atom having a relatively small atom compared to carbon and it can be understood as having vacancy-like characteristics, which has proved successful in explaining the electronic structure of the defects in a diamond [30].

In the positive charge state, three different symmetry configurations are obtained. The differences are within a few meV as listed in table 1 The lowest structure has $C_{2 v}$ symmetry lower than two other 
Table 1. Relative energies for different structures with different symmetries of $\mathrm{O}_{s}$. The zero of energy for neutral, positive and negative charged state is set to the $\mathrm{O}_{s}^{0} S=1 C_{2 v}, \mathrm{O}_{s}^{+1} S=1 / 2 C_{2 v}$ and $\mathrm{O}_{s}^{-1} S=1 / 2$ $C_{2 v}$, respectively.

\begin{tabular}{|c|c|c|c|}
\hline \hline Symmetry & Charge state & Spin configuration & Relative energy \\
\hline \hline$C_{3 v}$ & neutral & $S=0$ & $0.20 \mathrm{eV}$ \\
\hline$T_{d}$ & neutral & $S=0$ & $0.20 \mathrm{eV}$ \\
\hline$C_{2 v}$ & neutral & $S=0$ & $0.21 \mathrm{eV}$ \\
\hline$C_{3 v}$ & neutral & $S=1$ & $0.57 \mathrm{eV}$ \\
\hline$C_{3 v}$ & positive & $S=1 / 2$ & $0.04 \mathrm{eV}$ \\
\hline$T_{d}$ & positive & $S=1 / 2$ & $0.05 \mathrm{eV}$ \\
\hline$C_{3 v}$ & negative & $S=1 / 2$ & $0.57 \mathrm{eV}$ \\
\hline$T_{d}$ & negative & $S=1 / 2$ & $1.13 \mathrm{eV}$ \\
\hline \hline
\end{tabular}

structures by just $0.04 \mathrm{eV}$ for $C_{3 v}$ and $0.05 \mathrm{eV}$ for $T_{d}$ configuration, respectively, where all structures with spin $S=1 / 2$. The energy difference is so tiny that one cannot be certain which possesses the lowest energy. Similarly to $\mathrm{O}_{s}^{+}$, the $C_{2 v} S=1 / 2$ configuration is found to be favoured in the negatively charged state. Moreover, there are two other metastable configurations which are high in energy as listed in table 1

Electronically, we present the previously calculated energy structure of on-site configuration quoted by Gali et al. [18] that possesses the ground state configuration [figure 2(c)]. Its band gap consists of one

(a)

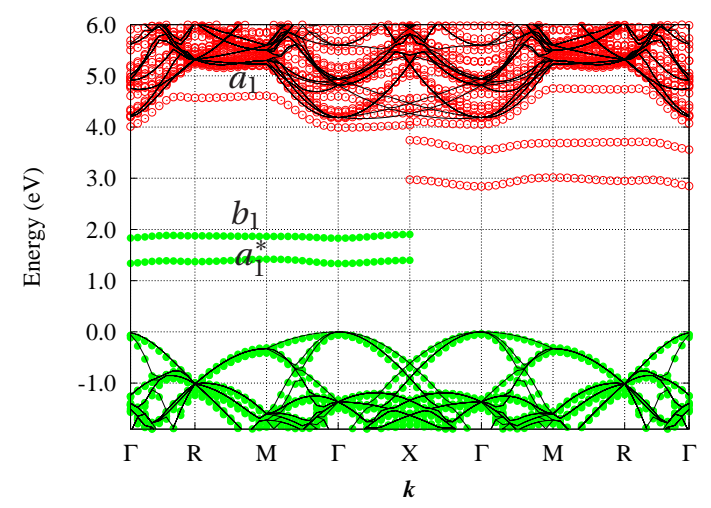

(b)

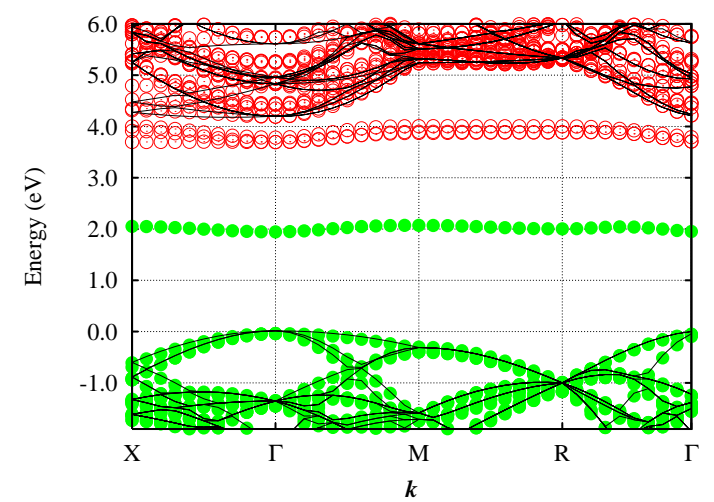

(c)

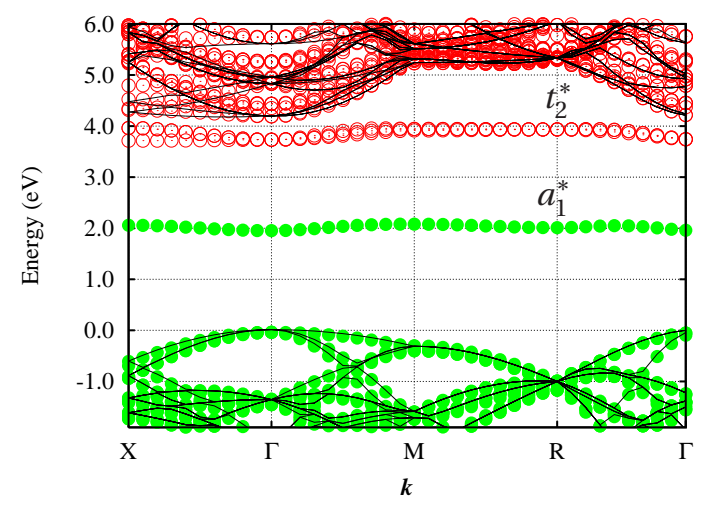

Figure 2. (Color online) Band structure for $S=1$ and $S=0$ configurations of substitutional oxygen in diamond. Filled and empty circles show filled and empty bands, respectively. The energy scale is defined by the valence band top at zero energy. (a) $C_{2 v} S=1$, (b) $C_{3 v} S=0$, (c) $T_{d} S=0$. 
fully non-degenerate one-electron states $a_{1}$ near the middle of the band gap and one triplet degenerate $t_{2}$ state close to the conduction band, with a total occupation of two electrons, where $a_{1}$ and $t_{2}$ levels are introduced in the band gap due to C vacancy [31]. Apparently, the $a_{1}$ and $t_{2}$ levels hybridized with oxygen valence states $s$ and $p$ atomic orbitals, which gives rise to four levels $a_{1}, t_{2}, a_{1}^{*}$ and $t_{2}^{*}$, two states will be in the band gap, the anti-bonding $a_{1}^{*}$ level will be occupied by two electrons and triplet degeneracy $t_{2}^{*}$ will be unoccupied.

Our calculation shows that $C_{2 v} S=1$ in the neutral charge state is the most stable structure, where the $t_{2}$-level is split into three levels, $b_{1} a_{1} b_{2}$ as shown schematically in figure 2 (a), where $b_{2}$ lies in the conduction band. The $b_{1}$ and $a_{1}$ levels are odd and even combinations of the neighbouring carbon dangling bonds which are farther apart than the other two to oxygen, respectively.

Other previous density functional calculations [18] found that $\mathrm{O}_{s}$ has $T_{d}$ symmetry and is the most stable configuration in neutral, negative and positive charge states. However, it is unclear whether the $S=1$ was considered. We find that the spin states for the neutral and positively charged states follow the Hund rule, so the positive and neutral defects have $S=1 / 2$ and $S=1$, respectively. Compared to the band gap of the well-known substitutional nitrogen (it has $C_{3 v}$ ), $\mathrm{O}_{s}$ with $C_{3 v} S=0$ symmetry has more levels. In addition to $a_{1}$ level associated with the radical on the unique carbon, there is one empty doublet degeneracy $e^{0}$ and a singlet empty $a^{0}$ from anti-bonding between $\mathrm{O}$ and there are three identical carbon atoms neighbouring the oxygen as shown in figure 2(b). The oxygen atom is more shared with the three close neighbours.

$\mathrm{O}_{s}$ is theoretically electrically active, with donor, double donor and acceptor levels being estimated to be at $E_{c}-2.8 \mathrm{eV}, E_{\nu}+0.04 \mathrm{eV}$ and $E_{c}-1.9 \mathrm{eV}$, respectively. These levels are in disagreement with the previous density functional calculation [18] of values $E_{v}+1.97 \mathrm{eV}, E_{v}+1.39 \mathrm{eV}$ and $E_{v}+2.89 \mathrm{eV}$, respectively. Oxygen can exhibit an amphoteric behaviour depending on the location of Fermi level. Since the acceptor level of oxygen lies below a donor level such as $\mathrm{N}_{s}$ and the donor level of oxygen lies above the acceptor level such as $V$ [32], one would expect the charge transfer to occur in the material containing both types of centres. Previously, in [14] we showed that Nitrogen-Oxygen complexes render both an acceptor and donor; we find the $(-/ 0)$ and $(0 /+)$ levels at $E_{v}+3.7 \mathrm{eV}$ and $E_{v}+1.5 \mathrm{eV}$.

Hyperfine tensors for the most stable configurations within different charge states of oxygen and four

Table 2. Calculated hyperfine tensors (MHz) of oxygen and the four nearest neighbour ${ }^{13} \mathrm{C}$ in substitutional $0 . \theta$ and $\phi$ are given relative to the directions $\langle 001\rangle$ and $\langle 100\rangle$, respectively.

\begin{tabular}{|c|c|c|c|c|c|c|}
\hline \hline Species & \multicolumn{2}{|c|}{$A_{1}$} & \multicolumn{2}{|c|}{$A_{2}$} & \multicolumn{2}{c|}{$A_{3}$} \\
\hline \hline \multicolumn{7}{|c|}{$C_{2 \nu}, S=1$} \\
\hline${ }^{17} \mathrm{O}$ & -198 & $(90,315)$ & -181 & $(00,00)$ & -165 & $(90,45)$ \\
\hline $\mathrm{C} 1$ & -1 & $(147,225)$ & -1 & $(90,135)$ & 4 & $(123,45)$ \\
\hline $\mathrm{C} 2$ & -1 & $(147,45)$ & -1 & $(90,135)$ & 4 & $(57,45)$ \\
\hline $\mathrm{C} 3$ & 205 & $(126,315)$ & 86 & $(90,45)$ & 86 & $(144,135)$ \\
\hline $\mathrm{C} 4$ & 205 & $(54,315)$ & 86 & $(90,45)$ & 86 & $(144,315)$ \\
\hline \multicolumn{7}{|c|}{$C_{2 v}$, charge $=+1, S=1 / 2$} \\
\hline${ }^{17} \mathrm{O}$ & -568 & $(00,129)$ & -552 & $(90,45)$ & -538 & $(90,315)$ \\
\hline $\mathrm{C} 1$ & 41 & $(125,45)$ & 18 & $(102,144)$ & 18 & $(142,250)$ \\
\hline $\mathrm{C} 2$ & 41 & $(55,45)$ & 18 & $(102,126)$ & 18 & $(142,20)$ \\
\hline $\mathrm{C} 3$ & 197 & $(125,315)$ & 86 & $(90,45)$ & 86 & $(145,135)$ \\
\hline $\mathrm{C} 4$ & 197 & $(55,315)$ & 86 & $(90,45)$ & 86 & $(145,315)$ \\
\hline \multicolumn{7}{|c|}{$C_{2 v}$, charge $=-1, S=1 / 2$} \\
\hline${ }^{17} \mathrm{O}$ & -19 & $(90,135)$ & 31 & $(00,00)$ & 40 & $(90,45)$ \\
\hline $\mathrm{C} 1$ & -7 & $(82,225)$ & -4 & $(172,224)$ & -4 & $(90,315)$ \\
\hline $\mathrm{C} 2$ & -7 & $(98,225)$ & -4 & $(172,46)$ & -4 & $(90,315)$ \\
\hline $\mathrm{C} 3$ & 238 & $(126,315)$ & 105 & $(90,45)$ & 105 & $(144,135)$ \\
\hline $\mathrm{C} 4$ & 238 & $(54,315)$ & 105 & $(90,45)$ & 105 & $(144,315)$ \\
\hline \hline
\end{tabular}




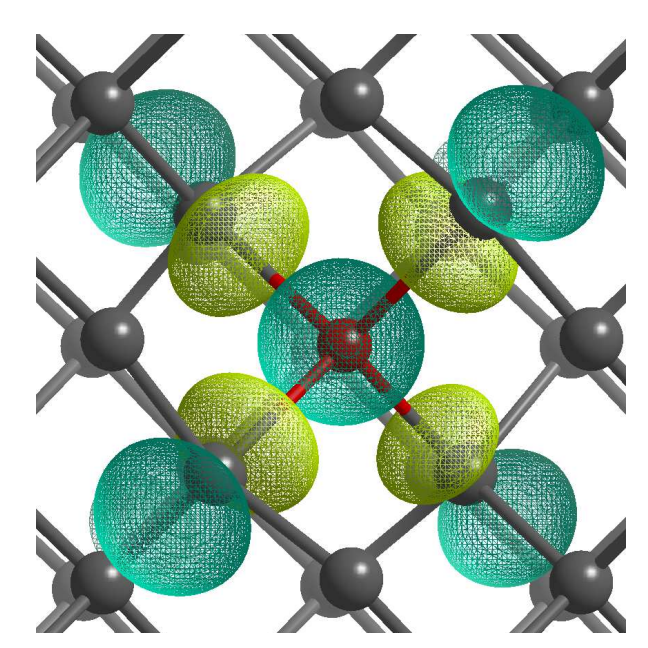

Figure 3. (Color online) Unpaired electron Kohn-Sham functions for positive substitutional oxygen with $\mathrm{C}_{3 v}$ symmetry.

nearest neighbours are listed in table 2 There are no hyperfine values for substitutional oxygen in literature so far. $\mathrm{O}_{s}^{+}$with $C_{3 v}$ structurally resembles $\mathrm{P} 1$ centre, although the present calculation shows that this configuration is metastable within a few meV. $C_{3 v}$ symmetry means that one of the four neighbouring $\mathrm{C}$ atoms is farther away from the oxygen than the other three, the hyperfine tensor on these carbon atoms is small ( $A_{\|}=89 \mathrm{MHz}, A_{\perp}=42 \mathrm{MHz}$ ) compared to those in P1 centre, which means that the spin density is not mostly localized on the carbon radical site. It is distributed on the anti-bond between $\mathrm{O}$ and four neighbouring carbon atoms as shown in figure 3 . In the negatively charged state with $C_{2 v}$ symmetry, the spin density is strongly localized in the vicinity of the carbon radical sites, leading to small, anisotropic hyperfine tensors for the oxygen, whereas in neutral charged state, the relatively larger values for the hyperfine $\mathrm{O}$ compared to the negatively charged state are due to the relatively big amount of spin density on the O-site, and to some extent on the carbon radical atoms, from odd and even combinations of the neighbouring carbon dangling bonds for the highest and second highest occupied levels, respectively. In the positively charged state, the even combinations of neighbouring carbon dangling bonds make the values of hyperfine tensor on $\mathrm{O}$ still larger.

\section{Conclusions}

We have used ab initio computational modelling mainly for the stability and electronic structure on different forms of the substitutional oxygen in diamond. Energetically we find that $S=0 C_{2 v}$ is the most stable structure where both $S=0$ and $S=1$ are considered.

The band gap of substitutional oxygen gives rise to two states, one $a_{1}$ state located near the middle of the band gap and the other $t_{2}$ state located close to the conduction band edge. The $t_{2}$ state is populated when $\mathrm{O}$ becomes negatively charged or neutral $S=1$ configuration.

\section{References}

1. Briddon P.R., Jones R., Physica B, 1993, 185, No. 1-4, 179; doi10.1016/0921-4526(93)90235-X

2. Jones R., Goss J., Pinto H., Palmer D., Diamond Relat. Mater., 2015, 53, 35; doi 10.1016/j.diamond.2015.01.002

3. Atumi M.K., Goss J.P., Briddon P.R., Shrif F.E., Rayson M.J., J. Phys.: Condens. Matter, 2013, 25, No. 6, 065802; doi $10.1088 / 0953-8984 / 25 / 6 / 065802$

4. Chrenko R., Phys. Rev. B, 1973, 7, 4560; doi 10.1103/PhysRevB.7.4560

5. Farrer R., Solid State Commun., 1969, 7, 685; doi 10.1016/0038-1098(69)90593-6

6. Crowther P.A., Dean P.J., Sherman W.F., Phys. Rev., 1967, 154, No. 3, 772; doi 10.1103/PhysRev.154.772

7. Prins J.F., Phys. Rev. B, 2000, 61, No. 11, 7191; doi 10.1103/PhysRevB.61.7191 
8. Walker J., Nature, 1976, 263, No. 275, 275; doi $10.1038 / 263275 a 0$

9. Melton C.E., Nature, 1976, 263, 309; doi 10.1038/263309a0

10. Ruan J., Choyke W.J., Kobashi K., Appl. Phys. Lett., 1993, 60, No. 12, 1379; doi 10.1063/1.108685

11. Mori Y., Eimori N., Kozuka H., Yokota Y., Moon H., Ma J.S., Ito T., Hiraki A., Appl. Phys. Lett., 1992, 60, No. 1, 47; doi $10.1063 / 1.107368$

12. Iakoubovskii K., Stesmans A., Phys. Rev. B, 2002, 66, No. 4, 045406; doi 10.1103/PhysRevB.66.045406

13. Ammerlaan C.A.J., In: Landolt-Börnstein Numerical Data and Functional Relationships in Science and Technology New Series Vol. III/22b, Schultz M. (Ed.), Springer, Berlin, 1989, 177-206.

14. Etmimi K.M., Goss J.P., Briddon P.R., Gsiea A.M., J. Phys.: Condens. Matter, 2010, 22, No. 38, 385502; doi $10.1088 / 0953-8984 / 22 / 38 / 385502$

15. Komarovskikh A., Nadolinny V., Palyanov Y., Kupriyanov I., Phys. Status Solidi A, 2013, 210, No. 10, 2074; doi $10.1002 /$ pssa.201300036

16. Palyanov Y.N., Borzdov Y.M., Khokhryakov A.F., Kupriyanov I.N., Sokol A.G., Cryst. Growth Des., 2010, 10, No. 7, 3169; doi 10.1021/cg100322p

17. Komarovskikh A., Nadolinny V., Palyanov Y., Kupriyanov I., Sokol A., Phys. Status Solidi A, 2014, 211, No. 10, 2274; doi $10.1002 /$ pssa.201431163

18. Gali A., Lowther J.E., Deák P., J. Phys.: Condens. Matter, 2001, 13, 11607; doi 10.1088/0953-8984/13/50/319.

19. Perdew J.P., Burke K., Ernzerhof M., Phys. Rev. Lett., 1996, 77, 3865; doi 10.1103/PhysRevLett.77.3865

20. Briddon P.R., Jones R., Phys. Status Solidi B, 2000, 217, No. 1, 131; doi 10.1002/(SICI)1521-3951(200001)217:1\%3C131::AID-PSSB131\%3E3.0.CO;2-M

21. Rayson M.J., Briddon P.R., Comput. Phys. Commun., 2008, 178, No. 3, 128; doi 10.1016/j.cpc.2007.08.007.

22. Monkhorst H.J., Pack J.D., Phys. Rev. B, 1976, 13, No. 12, 5188; doi 10.1103/PhysRevB.13.5188

23. Goss J.P., Shaw M.J., Briddon P.R., In: Theory of Defects in Semiconductors, Drabold D.A., Estreicher S.K. (Eds.), Springer, Berlin/Heidelberg, 2007, 69-94; doi 10.1007/11690320_4

24. Sze S.M., Physics of Semiconductor Devices, 2nd Edn., Wiley-Interscience, New York, 1981.

25. Liberman D.A., Phys. Rev. B, 2000, 62, No. 11, 6851; doi 10.1103/PhysRevB.62.6851

26. Hartwigsen C., Goedecker S., Hutter J., Phys. Rev. B, 1998, 58, No. 7, 3641; doi 10.1103/PhysRevB.58.3641

27. Shaw M.J., Briddon P.R., Goss J.P., Rayson M.J., Kerridge A., Harker A.H., Stoneham A.M., Phys. Rev. Lett., 2005, 95, 205502; doi 10.1103/PhysRevLett.95.205502

28. Blöchl P.E., Phys. Rev. B, 1994, 50, No. 4, 17953; doi 10.1103/PhysRevB.50.17953

29. Rayson M.J., Phys. Rev. E, 2007, 76, No. 2, 026704; doi 10.1103/PhysRevE.76.026704

30. Watkins G.D., Physica B, 1983, 117-118, No. 1-3, 9; doi 10.1016/0378-4363(83)90432-1

31. Coulson C.A., Kearsley M.J., Proc. R. Soc. London, Ser. A, 1957, 241, 433; doi 10.1098/rspa.1957.0138

32. Dannefaer S., Pu A., Kerr D., Diamond Relat. Mater., 2001, 10, 2113; doi 10.1016/S0925-9635(01)00489-7

\title{
Дослідження методом теорії функціоналу густини кисню заміщення в алмазі
}

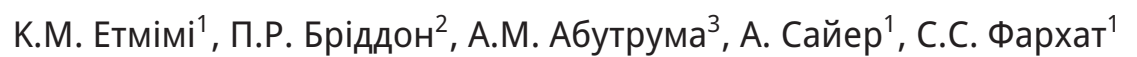 \\ 1 Фізичний відділ, факультет природничих наук, Університет Тріполі, Тріполі, Лівія \\ 2 Коледж електричної, електронної і комп'ютерної інженерії, Університет Ньюкасла, \\ Ньюкасл-апон-Тайн, Великобританія \\ 3 Вищий інститут комплексних професій, Тріполі, Лівія
}

Останнім часом представлено декілька досліджень стосовно наявності кисню в алмазі, наприклад теоретично і експериментально призначена модель для N3 EPR створена з комплексу заміщувального азоту та заміщувального кисню як найближчих сусідів. У цій статті представлено ab initio обчислення заміщувального кисню в алмазі з огляду на стійкість, електронні структури, геометрію та надтонку взаємодію, а також показано, що заміщувальний кисень $3 \mathrm{C}_{2 v}, \mathrm{~S}=1 \epsilon$ конфігурацією основного стану. Встановлено, що кисень продукує або ж донорний, або акцепторний рівень в залежності від положення Фермі рівня.

Ключові слова: теорія функціоналу густини, алмаз, кисень, надтонка взаємодія 


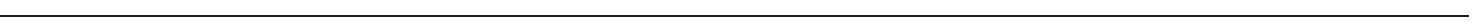

